\title{
Active power measurement in arc welding and its role in heat transfer to the plate
}

\author{
Vinicius Lemes Jorge ${ }^{1}$ • Raul Gohrs ${ }^{2}$ • Américo Scotti ${ }^{1,3}$
}

Received: 14 February 2017 / Accepted: 11 April 2017 /Published online: 24 April 2017

(C) The Author(s) 2017. This article is an open access publication

\begin{abstract}
A contemporary paper claimed that a method using the resistance of impedance (active power) for arc power calculation is more accurate than the conventional approach, with consequences on the actual heat transfer to the plate. However, despite the comprehensive reasoning, no heat-related results are shown in this intriguing paper to support the claim. Thus, the aim of this work was to apply the proposed method for determining the weight of active power in the total arc power. A series of weldments was carried out, by using GTAW in constant and pulsed current modes and short-circuiting GMAW with different inductance settings. The effect of the active power on the heat transfers to the plate was assessed by both bead crosssection geometries and calorimetry. The results showed that even a significant fraction of active power of the total power
\end{abstract}

Recommended for publication by Study Group 212 - The Physics of Welding

Américo Scotti

ascotti@ufu.br; americo.scotti@hv.se

Vinicius Lemes Jorge

viniciuslemesj@hotmail.com

Raul Gohrs

rgj@imc-soldagem.com.br

1 Center for Research and Development of Welding Processes of the Federal University of Uberlandia, Uberlandia, MG 38400-902, Brazil

2 IMC Soldagem, Palhoça, SC 88133-513, Brazil

3 Production Technology West, University West, SE-461 86 Trollhättan, Sweden was reached, no changes in bead geometry or heat input were found. A review of the assumptions used in the primal paper showed that an arc is better represented by an ER circuit than by an RLC circuit. As a conclusion, the arc as a reactance-free load presents no component such as nonactive power and the conventional approaches are accurate methods to measure arc power, representing the actual active power.

Keywords (IIW Thesaurus) Arc power - Active power Energy input $\cdot$ Arc model

\section{Introduction}

Electric arc welding is a means of manufacturing that allows for the joining of parts by fusion through the usage of heat derived from the conversion of electric power. The energy that is produced by the electric arc and transferred onto/into a plate (heat input) is extremely important, not only for weld bead geometric formation but also for metallurgical transformations, influencing the mechanical proprieties of the joint. Moreover, heat input is proportional to the arc energy, which in turn is a ratio of arc power and arc travel speed. Thus, the arc power rating is a determinant factor to quantify the heat provided. However, the methods for welding energy/arc power determinations give rise to discussions among researchers.

Literature shows differences in opinion between authors regarding the methods that should be used to determine arc power, if arithmetical average power, effective average power or average instantaneous power, respectively quantified by Eqs. 1, 2, and 3 (where $U_{\mathrm{m}}$ and $I_{\mathrm{m}}$ are the average of voltage and current measured values, $U_{\text {ef }}$ and $I_{\text {ef }}$ are 
voltage and current RMS calculated values, $U(k)$ and $I(k)$ are the instantaneous voltage and current measured values and $n$ is the number of samples).

$P_{\text {arithmetical }}=U_{\mathrm{m}} \cdot I_{\mathrm{m}}$

$P_{\text {effective }}=U_{\text {ef }} \cdot I_{\mathrm{ef}}$

$P_{\text {inst }}=\frac{1}{n} \sum_{k=1}^{n} U(k) \cdot I(k)$

Bosworth [1] has found that the differences of applying the different methods on the final value can reach $30 \%$. Joseph et al. [2], using calorimetry, stated that the only measure of welding energy which is reasonably well correlated to current variations is based on the instantaneous power. Nascimento et al. [3] analysed all the methods mentioned above and the respective consequences on the heat input and thermal efficiency calculations. They claimed that the arithmetic mean power method can be applied in a few cases, in which there is no oscillation in current and voltage (like in spray transfer gas metal arc welding), but it is safer to use the average instantaneous power method (more laborious, yet generic). They supported their claim based on the expectance theorem, which says that the product of the means of two discrete variables is the same as the mean of the product of these variables only if the variables are independent of each other. More recently, Melfi [4] showed that the method to calculate heat input, using average instantaneous energy, was added to the 2010 edition of the ASME Boiler and Pressure Vessel Code: Section IX (item QW409.1) for waveform-controlled welding. The ISO/TR 18491:2015 standard is also using this method in the guidelines for measurement of welding energies. The concept of Eq. 3 is the integral of power (different from Eqs. 1 and 2), thus applicable to any current (DC and $\mathrm{AC}$ ) and welding conditions (from steady constant current to unsteady pulsed current). Thus, average instantaneous power seems to be gaining acceptance in the welding community.

However, a newly proposed approach by Wong and Ling [5] instigates curiosity. The authors initially explain that the conversion of electricity into heat in arc welding is traditionally given by Joule's law, as basically demonstrated in Eq. 4 (using the symbologies and interpretation from the authors of the current paper), where $P_{\mathrm{R}}$ is known as the heat value generated by arc power in fusion welding; $I_{\mathrm{m}}$ is the mean welding current value, obtained by averaging the instantaneous measured values of current; and $R$ (if replacing $R$ ) would stand for the ohmic circuit resistance value, usually calculated from the ratio of mean values of voltage $\left(U_{\mathrm{m}}\right)$ and current $\left(I_{\mathrm{m}}\right)$. A support for Wong and Ling's explanation would be the fact that many authors consider the arc behaving as an electrical resistance, as cited in Kodama et al. [6], Ngo et al. [7] and Terasaki and Simpson [8]. Nonetheless, still according to Wong and Ling [5], the measurement of resistance is not as easy as current measurement, because there is no direct measuring method to obtain the resistance. Therefore, an indirect measuring method (considering a merely resistive arc) has to be used, such as in Eq. 5, in which $R$ is the average value of the instantaneous ohmic resistance, $U(k)$ and $I(k)$ are the instantaneous voltage and current measured values and $n$ is the number of samples.

$P_{\mathrm{R}}=R \cdot I_{\mathrm{m}}$

$R=\frac{1}{n} \sum_{k=1}^{n} \frac{U(k)}{I(k)}$

However, under Wong and Ling's [5] reasoning, a welding arc cannot be treated as a single electrical resistance, due to selfinduced magnetic flux surrounding the arc. In another publication, Wong and Ling [9] further detailed a welding system represented by an equivalent circuit, consisting of a resistor $\mathrm{R}$, inductor $\mathrm{L}$ and capacitor $\mathrm{C}$ connected in series (an RLC circuit). Thus, the arc power calculated by Eq. 4, from voltage and current signals as measured by instrumentation means, is in fact composed of two components, a real part (due to resistance) and an imaginary part (due to reactance). The key fact is that Wong and Ling [5] suggest that the calculation to assess the arc power rating should expunge the imaginary part of the power rating, if heat transfer to the plate is the target. Trying to explain Wong and Ling's concepts, the power that is converted into heat would represent basically the resistive power portion of the welding circuit. However, inductive $(\mathrm{L}(\mathrm{t}))$ and capacitive $(\mathrm{C}(\mathrm{t}))$ are portions of the electric power conserved as reactance, so that they are not responsible for energy dissipation as heat. Thus, the power rating in an electric arc free of the reactance effects would be a more reliable approach.

Wong and Ling [5] state that the capacitance and inductance effects in an electrical signal from arc welding are represented by the impedance of equivalent system $Z_{\text {in }}(t)$. The input electrical impedance $Z_{\text {in }}(t)$ of the equivalent circuit is obtained by probing the welding voltage and current simultaneously at the input port of the welding system. Conventionally, the signal processing of $Z_{\text {in }}(t)$ is carried out by applying the Fourier transform to the signals and later by calculating the result in the frequency domain. However, the drawback of this approach would be that the result does not reflect $Z_{\text {in }}(t)$ in real time. Therefore, the Hilbert transform was employed by Wong and Ling to calculate the time varying $Z_{\text {in }}(t)$. The Hilbert transform of a real valued time domain signal, $x(t)$ (where ' $x$ ' is the variable in analyses, which means either voltage or current in this article), yields the original signal in its analytic form, $x(t)=x(t)+j h[x(t)]$. Although the analytic signal is defined as a magnitude function of $A(t)$ and 
an instantaneous phase function of $\theta(t)$, the Hilbert transform is different from the Fourier transform. This feature is especially important to obtain $Z_{\text {in }}(t)$, because it is capable of providing the time-varying properties of the welding system. The impedance may be presented in a polar or in a complex form that is usually more convenient to be used. Henceforth, $Z_{\text {in }}(t)$ shows a real part ' $Z_{\mathrm{r}}(t)$ ' and an imaginary part ' $Z_{\mathrm{x}}(t)$ '. The last one is composed of inductive ' $\mathrm{L}(\mathrm{t})$ ' and capacitive ' $\mathrm{C}(\mathrm{t})$ ' portions.

In summary, Wong and Ling based their reasoning upon errors that may occur by using Ohm's law in order to calculate the power rating, because the welding arc's physical behaviour could not be described as a phenomenon strictly resistive. To that extent, the concept of Eq. 4, aiming at the conversion of electric power into heat in arc welding, should not be applied. In addition, by applying the Hilbert transform, Wong and Lin demonstrated that an arc power based on $Z_{\mathrm{r}}(t)$, Eq. 6, is always lower than the arc power obtained by $P_{\text {inst }}$, because $Z_{\mathrm{r}}(t)$ is lower than $R . Z_{\mathrm{r}}(t)$ would be the resistance of the welding system expunging the influence of inductance, obtained by the Hilbert transform.

$P_{\mathrm{Zr}}=Z_{\mathrm{r}}(t) \cdot I_{\mathrm{m}}^{2}$

Therefore, following Wong and Ling's thinking and giving names to their calculated powers, one could say that the inductive portion of the actual arc power can be subtracted out of the hereafter referred to as 'Wong and Ling's gross power' $\left(P_{\mathrm{R}}\right)$, Eq. 4. Consequently, a more realistic power representation can be reached (Eq. 6), which is related to heat transfer to the plate and hereafter referred to as 'Wong and Ling's active power' $\left(P_{\mathrm{Zr}}\right)$, due to semblance to the terminology of utilitysupplied AC power. And in some welding processes in which the variation of current is prominent (pulsed GMAW or GTAW, short-circuiting GMAW, etc., or even a conventional welding with the ground cable coiled), the weight of the difference between $P_{\mathrm{R}}$ and $P_{\mathrm{Zr}}$ (difference hereafter referred to as non-active power $\left.\left(P_{\mathrm{R}-\mathrm{Zr}}\right)\right)$ becomes significant. Thus, according to Wong and Ling, Eq. 4 should not be applied to measurements of arc power in arc welding.

Despite the inquisitiveness behind Wong and Ling's theory [5], Eqs. 1 and 2 (and, most recently, also Eq. 3) have been conventionally used for a long time in arc welding to determine arc power and the correlated heat input. The demonstration of a potential inaccuracy of these equations would raise serious consequences for welding technology. In addition, Wong and Ling have not demonstrated in their paper the quantitative contribution of the active portion of the total power to the actual heat transferred onto/into the plate. Thus, the objective of this work was to evaluate the method proposed by Wong and Ling, comparing with the conventional methods, and to determine the potential weight of Wong and Ling's active power on formation of weld beads.

\section{Experimental procedure}

The experimental procedure was split into three stages. In the first stage, different ratios of Wong and Ling's gross and active powers were pursued by welding with GTAW at constant and pulsed currents. The effect of these different ratios on the bead geometry was evaluated. In the second stage, the same approach was applied, yet with other parameterization, to verify the consistency of the trends. To complement the analysis, the heat absorbed by the test plates in calorimetric measurements was also analysed. Finally, in the third stage, the welding process was exchanged to short-circuiting GMAW and the different ratios of gross and active energies were reached by changing the inductance in the power source.

Data acquisition (voltage and current) was carried out by an $\mathrm{A} / \mathrm{D}$ board at a rate of $5 \mathrm{kHz}$ and 14 bits, for 10 to $30 \mathrm{~s}$ each run. The voltage probe was attached to both contact tips and plate support, to eliminate the inductive effect of the power source cables. The data were compiled by a dedicated software, using a MATLAB $\AA$ platform. A digital $100-\mathrm{Hz}$ FFT low-pass filter was used on the voltage and current data, to keep the data analysis condition as close as possible to Wong and Ling's paper [5], even though being aware that such a low-pass band limit would distort the waveforms. Wong and Ling's gross power $\left(P_{\mathrm{R}}\right)$ was calculated using Eq. 4, while Wong and Ling's active power $\left(P_{\mathrm{Zr}}\right)$ was reached using Eq. 6. The average instantaneous power $\left(P_{\text {inst }}\right)$ was also calculated (Eq. 3), since the calculation method is now applied in welding technology and it would have the same meaning as that of the gross power $P_{\mathrm{R}}$ proposed by Wong and Ling. However, in this section, the power analysis will be concentrated on Wong and Ling's calculation methods, since they are the target of the study. $P_{\text {inst }}$ is presented in the results only to emphasize the differences from and similarities to $P_{\mathrm{R}}$.

\subsection{Stage 1: constant $\times$ pulsed current in the GTAW process}

A secondary chopper power source (IMC MTE Digitec 600) was used for welding, in GTAW (constant current) mode. Bead-on-plate welding was carried out on ASTM 1020 test plates of $198 \times 38 \times 9.5 \mathrm{~mm}$, using a 4-mm diameter E3 Tungsten EWG electrode (AWS Spec. A5.12M/ A5.12:2009), with an included angle of $30^{\circ}$ and with an electrode-plate distance of $2 \mathrm{~mm}$. The weldments were shielded by pure argon at a flow rate of $13 \mathrm{l} / \mathrm{min}$. The experimental design was according to Table 1 .

Figure 1 presents the values of average instantaneous, gross and active powers of the runs from Table 1. No inductance effect was expected in constant current (run 1), i.e. active power was almost the same as the gross or average instantaneous power. The use of pulsing made the difference between 
Table 1 Parameterization of the runs from stage 1, at the same setting mean current $(335 \mathrm{~A})$ and travel speed $(12 \mathrm{~cm} / \mathrm{min})$

\begin{tabular}{lllll}
\hline Run & $I_{\mathrm{b}}(\mathrm{A})$ & $I_{\mathrm{p}}(\mathrm{A})$ & Freq. $(\mathrm{Hz})$ & $\Delta I(\mathrm{~A})$ \\
\hline 1 & - & 350 & - & - \\
2 & 300 & 400 & 5 & 100 \\
3 & 200 & 500 & 5 & 300 \\
4 & 200 & 500 & 10 & 300 \\
\hline
\end{tabular}

these powers relevant. The higher the pulsing $\Delta I$ (difference between pulse and base currents), the larger the distance between active and gross powers (runs 2 to 3 ). However, for the same $\Delta I$ but increasing pulsing frequency (runs 3 to 4 ), this difference remained almost the same. The power values varied according to the parameters, even though mean current was set the same (voltage increased towards the pulsed conditions). However, $P_{\text {inst }}$ differs from $P_{\mathrm{R}}$ due to the calculation methods, despite the similar meanings.

From the thermal point of view, bigger bead cross-sections (fused areas) would be expected as gross power is increased (if the travel speed is the same, arc power is proportional to arc energy). As seen in Fig. 2, this trend is observed for runs 2, 3 and 4 (pulsed current), yet diverging from the result from run 1 (constant current). This might be explained based on Silva and Scotti's [10] citation that bead geometry does not depend on thermal effects only but also on mechanical effects, more intense for pulsing currents. However, even limiting the analysis only to the pulsed current runs, the effect of the active power on the bead geometry cannot be easily separated from the Wong and Ling's gross power (the reason is that the bead cross-section areas increased accordingly to both gross and active powers).

Trying to separate the effect of the active power on the bead cross-section areas, the powers were normalized, taking run 1 as reference. The new fused areas were estimated in the same proportion as the variations of the powers in relation to the reference power. As seen in Fig. 3, for the same gross power

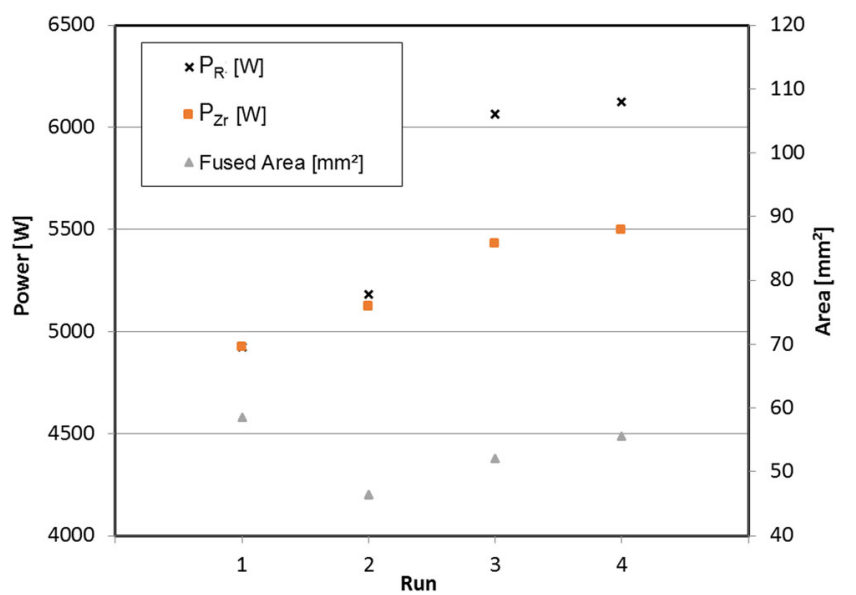

Fig. 2 Relationship between the bead cross-section area (fused areaaverage of three cross-sections) and Wong and Ling's gross $\left(P_{\mathrm{R}}\right)$ and active $\left(P_{\mathrm{Zr}}\right)$ powers

and analysing again only the pulsed conditions (runs 2, 3 and 4), the areas were approximately the same. The deviation of these results to run 1 persists. Applying the same approach to the active power, the results showed similarities. It is important to mention that the low number of experiments and no replications, since the objective was to reach only clear trends, do not allow for pointing out small differences. Therefore, it is not possible to state that either active power or gross power would be the governing factor on bead formation. On the other hand, one cannot say either that active power has no effect on the bead geometry, based on the same reasoning that bead formation depends on both thermal and mechanical effects (different pulsing condition likely presents different mechanical effect).

\subsection{Stage 2: constant $\times$ pulsed current in GTAW supported by calorimetry}

The same power source used in stage 1 was employed (GTAW constant current static characteristic). Bead-on-plate welding was carried out on a thinner plate (ASTM 1020 test plates of
Fig. 1 Values of average instantaneous $\left(P_{\text {inst }}\right)$ and Wong and Ling's gross $\left(P_{\mathrm{R}}\right)$ and active $\left(P_{\mathrm{Zr}}\right)$ powers from the different parameterizations in Table 1

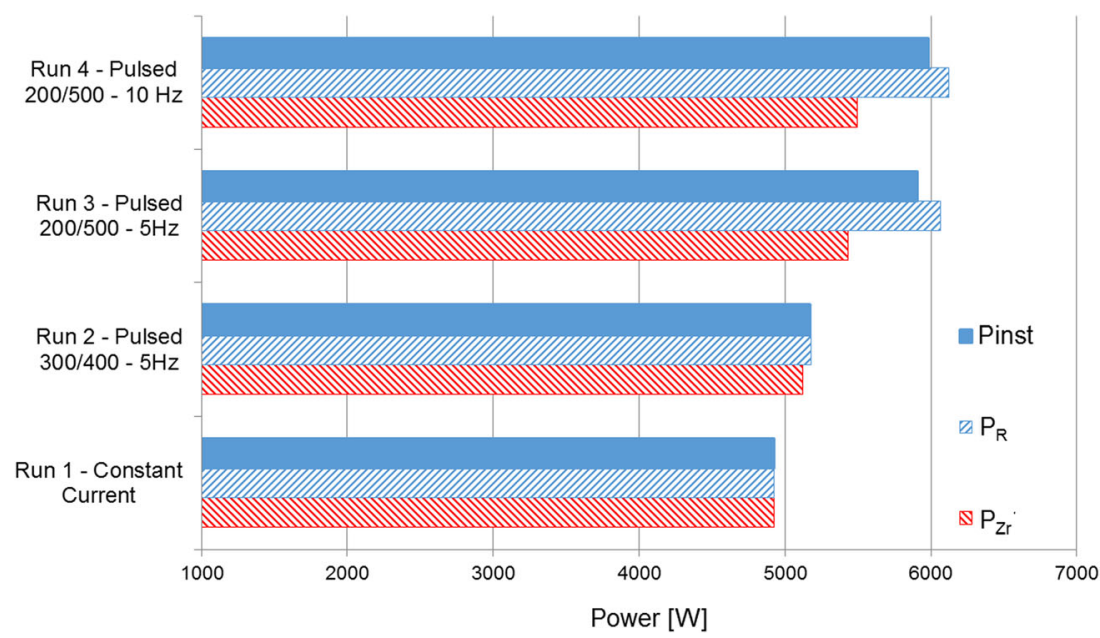



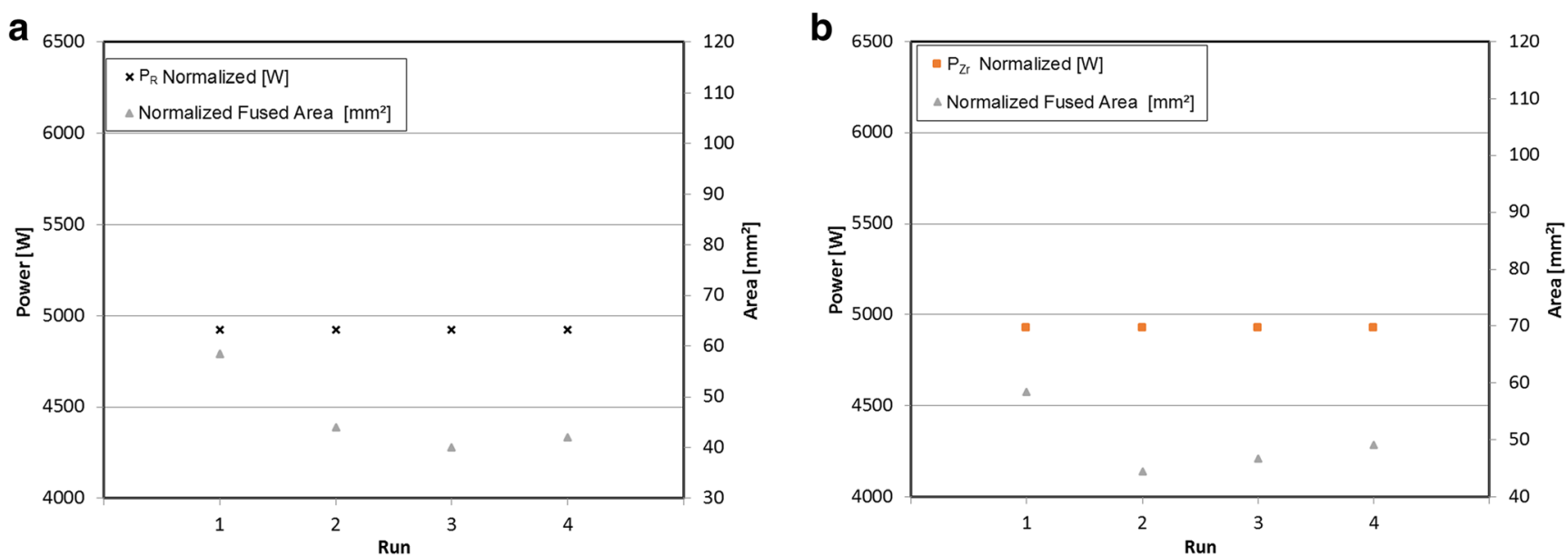

Fig. 3 a Relationship between the bead cross-section area (fused area - average of three cross-sections) and the gross power $\left(P_{\mathrm{R}}\right)$ after normalization. b Relationship between the bead cross-section area and the active $\left(P_{\mathrm{Zr}}\right)$ power after normalization

$200 \times 100 \times 6.3 \mathrm{~mm}$ ) to increase the scope of the results. A 4mm AWS EWTh2 electrode (angled to $60^{\circ}$ ) was used, with an electrode-plate distance of $3.5 \mathrm{~mm}$. The weldments were shielded by pure argon at a flow rate of $15 \mathrm{l} / \mathrm{min}$. The experimental design concerning the parameterization was according to Table 2. As seen, there are three increasing values of mean current of DC with no-pulse operation mode $(\Delta I=0)$, for which inductance effect is not expected, and three pulse current combinations, taking $200 \mathrm{~A}$ as the average value $(\Delta I$ of 100,200 and $300 \mathrm{~A}$ ), with expected inductance effect (the same pulse and base durations were chosen $-t_{\mathrm{p}}=t_{\mathrm{b}}=0.25 \mathrm{~s}$, giving a pulsing frequency of $2 \mathrm{~Hz}$ ). The travel speed used was $12 \mathrm{~cm} / \mathrm{min}$ in an automated linear torch carrier.

As seen in Fig. 4, if current is constant and increasing (runs 1,2 and 3 , where $\Delta I=0$ ), active powers, yet higher at each current level, are again almost the same as the gross/average instantaneous powers, regardless of the current intensity. However, the difference between the powers became relevant when using pulsing (runs 4,5 and 6 , where $\Delta I>>0$ ). The higher the pulsing $\Delta I$ (pulse and base currents), the larger the difference between active and gross powers.

Aiming to expand the basis for the analysis of heat transfer from the arc onto/into the plate, absorbed heat by the plate during the weldments was also evaluated together with the resultant cross-section area of the beads. Even though being aware of the limitations of calorimetric methods for heat input measurement, as stated by Hurtig et al. [11] and Liskevych et al. [12], a fully automated cryogenic calorimeter, as described by Liskevych and Scotti [13], was used. Different from that recommended in the latter citation, all comparisons were carried out following just one test condition to economize resources, i.e. plate trajectory of $395 \mathrm{~mm}$ and bead lengths of $40 \mathrm{~mm}$. In order to minimize (yet impossible of avoiding) the intrinsic errors due to heat losses before measurement, the test plates had large and fixed dimensions $(200 \times 100 \times 9.56 \mathrm{~mm})$.

From the thermal point of view, both higher absorbed heat from the calorimetric measurements and bigger bead crosssections as the gross power is increased (and so the arc energy) would be expected. As seen in Fig. 5, these trends were observed as much as for constant current experiments (run 3 towards 1) as for pulsed current experiments (run 4 towards 6). However, one can also deduce from Fig. 5 that active power proportionally decreases from runs 4 to 6 (the difference between gross and active powers enlarges), although both cross-section areas and absorbed heat increased. One
Table 2 Parameterization of the runs from stage 2

\begin{tabular}{|c|c|c|c|c|c|c|c|c|c|}
\hline \multirow[t]{2}{*}{ Identification } & \multirow[t]{2}{*}{ Runs } & \multicolumn{4}{|c|}{ Setting parameters } & \multicolumn{4}{|c|}{ Monitored parameters } \\
\hline & & $I_{\mathrm{m}}(\mathrm{A})$ & $I_{\mathrm{p}}(\mathrm{A})$ & $I_{\mathrm{b}}(\mathrm{A})$ & $f_{\mathrm{p}}(\mathrm{Hz})$ & $I_{\mathrm{m}}(\mathrm{A})$ & $I_{\text {rms }}(\mathrm{A})$ & $U_{\mathrm{m}}(\mathrm{V})$ & $U_{\text {rms }}(\mathrm{V})$ \\
\hline \multirow[t]{3}{*}{$\Delta I 0$} & 1 & 249 & - & - & - & 251 & 251 & 12.9 & 12.9 \\
\hline & 2 & 224 & - & - & - & 225 & 225 & 12.6 & 12.6 \\
\hline & 3 & 206 & - & - & - & 206 & 206 & 12.9 & 12.9 \\
\hline$\Delta I 100$ & 4 & 200 & 250 & 150 & 2 & 200 & 206 & 12.6 & 12.6 \\
\hline$\Delta I 200$ & 5 & & 300 & 100 & 2 & 202 & 225 & 12.9 & 13 \\
\hline$\Delta I 300$ & 6 & & 350 & 50 & 2 & 199 & 249 & 12.5 & 12.8 \\
\hline
\end{tabular}




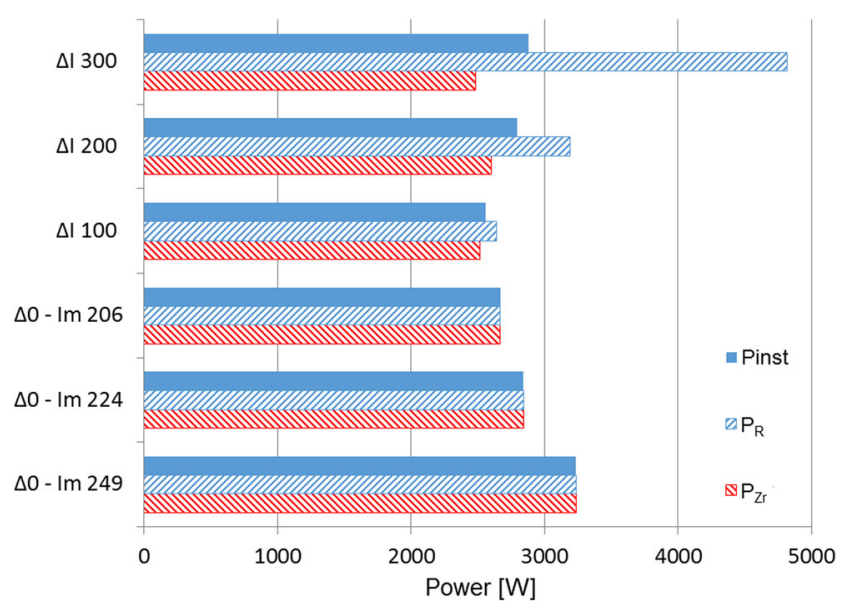

Fig. 4 Values of average instantaneous $\left(P_{\text {inst }}\right)$ and Wong and Ling's gross $\left(P_{\mathrm{R}}\right)$ and active $\left(P_{\mathrm{Zr}}\right)$ powers from the different parameterizations in Table 2

must remember that as seen in Fig. 4, although numerically different, $P_{\text {inst }}$ is proportional to $P_{\mathrm{R}}$; the difference between instantaneous power and active power would also enlarge. This suggests that both thermal parameters are governed by the gross power (whatever the means of calculation) rather than by the active power.

\subsection{Stage 3: variation of active power through inductance setting in GMAW}

Up to now, power component free of reactance (active power) was reached using Wong and Ling's calculations when pulsing current in GTAW was used. However, from this approach, mechanical action of the arc on the bead formation is also changed as pulsed parameters are altered. In this stage, short-circuiting GMAW was used, since from shortcircuiting transfer, low mechanical effect on bead formation

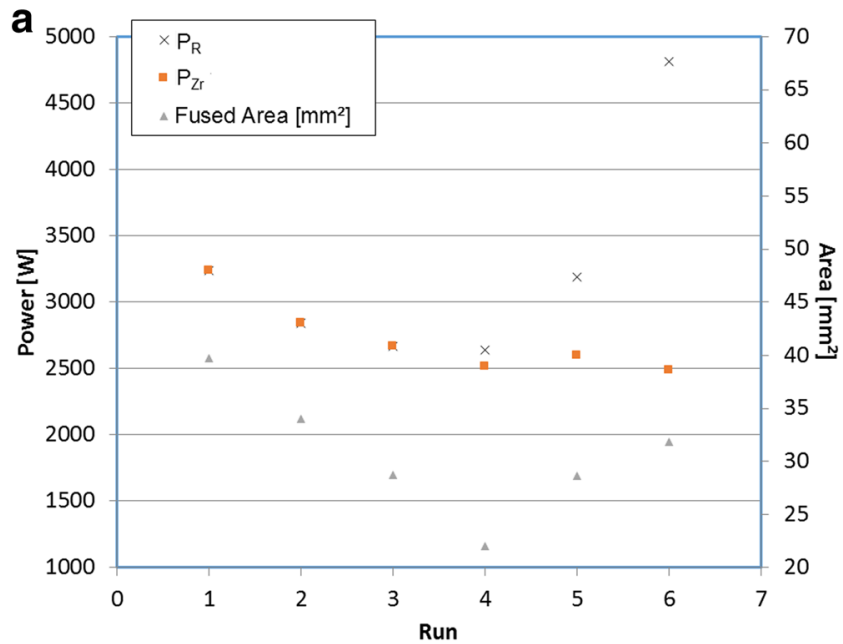

is expected (low arc length, low arc pressure, low droplet momentum). Moreover, mechanical effect has been blamed in this paper as a potential disguising effect of the arc power on bead formation. For that, an inverter power source was used to deposit beads on $150 \times 38 \times 6 \mathrm{~mm}$ plates of ASTM 1020 steels. There were three experiments with varying inductance settings in the power source $(-10$, off and +10 , meaning lower, medium and higher inductance), while the other important parameters were held the same, as follows: wire diameter $=1.2 \mathrm{~mm}$; AWS ER70S-6; contact-tip-to-work distance $=12 \mathrm{~mm}$; welding speed $=4.2 \mathrm{~mm} / \mathrm{s}$; leading angle $=90^{\circ}$; shielding gas $=\mathrm{Ar}+25 \% \mathrm{CO}_{2}$ at $14 \mathrm{l} / \mathrm{min}$; setting voltage $=19 \mathrm{~V}$; wire feed speed $=2.84 \mathrm{~m} / \mathrm{min}$. The resultant monitored parameters are expressed in Table 3.

Figure 6 presents the values of average instantaneous, active and gross powers of each experiment. The gross powers of the three experiments increased slightly from the lowest inductance to the highest one. However, the active power presents significant difference among the runs, turning smaller as inductance increases (increasing the portion of the nonactive power).

Besides bead cross-section areas, heat-affected zone (HAZ) areas were also determined, excluding the bead area in the plate cross-section. As seen in Fig. 7, the difference between Wong and Ling's gross and active powers increases when inductance is set at higher values (runs 1 to 3 ), suggesting an inductance effect. In addition, active power and the areas (fused and HAZ) have the same trends, which would support Wong and Ling's claim. However, there might be other side effects of the process acting together in the bead heat transfer onto/into the plate (bead and HAZ formation); a higher inductance normally increases the short-circuit duration, reduces the arcing time and increases the average current. Higher average current increases the gross power; shorter arcing time reduces the heat transferred to the plate.

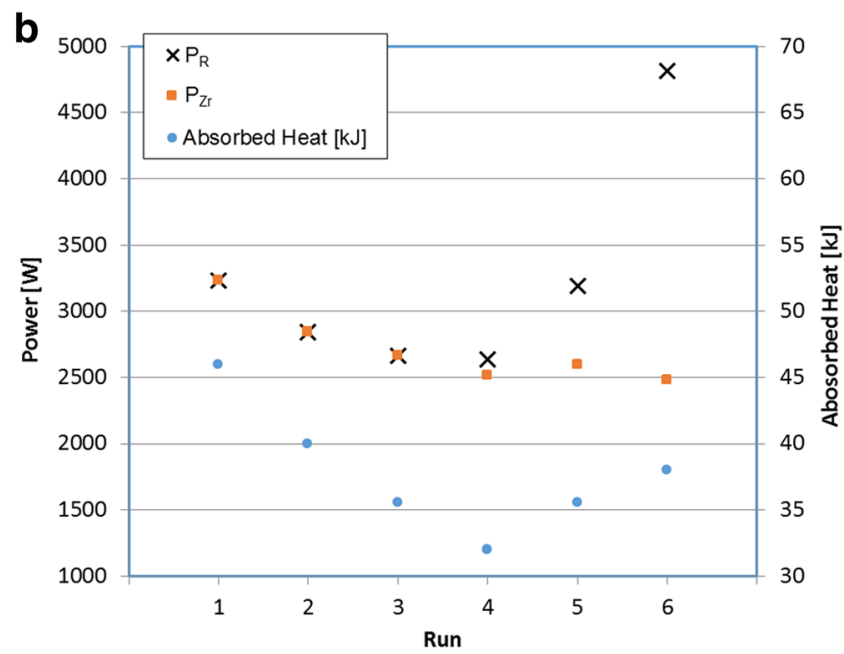

Fig. 5 Relationship between bead cross-section area (fused area - average of three cross-sections) (a) and plate absorbed heat (b) and Wong and Ling's gross $\left(P_{\mathrm{R}}\right)$ and active $\left(P_{\mathrm{Zr}}\right)$ powers 
Table 3 Monitored parameters of the runs from stage 3

\begin{tabular}{llll}
\hline Run & $I_{\mathrm{m}}(\mathrm{A})$ & $I_{\mathrm{rms}}(\mathrm{A})$ & $V_{\mathrm{m}}(\mathrm{V})$ \\
\hline 1-(-10) inductance setting & 145.1 & 147.4 & 18.9 \\
2-(off) inductance setting & 145.9 & 151.9 & 19.0 \\
3-(+10) inductance setting & 143.2 & 156.8 & 19.0 \\
\hline
\end{tabular}

\section{Discussion of results and a presentation of an alternative model of a welding arc}

The results presented in this work confirm that, if the method proposed by Wong and Ling [5] is applied, there is a portion of active power in the gross arc power signal when reactance is forced in the electrical circuit, such as by pulsing the current or short-circuiting the arc. By means of the Hilbert transform, an envelope of a time signal can be calculated and the active power component $\left(P_{\mathrm{Zr}}\right)$ can be separated from the gross power signal $\left(P_{\mathrm{R}}\right)$. However, no evidence was found to say that a smaller portion of $P_{\mathrm{Zr}}$ in the $P_{\mathrm{R}}$ value would mean reduction of the heat transfer onto/into the plate. The reasons for this lack of fitting could be the inexistence of induction in the arc (imprecise choice of a model for the arc), a signal distortion due to filtering and an unsuitable application of the Hilbert transform in this system.

Observing Fig. 8, one can note that the voltage and current traces in actual arc welding are in phase, even taking as an example an experiment in which the difference between Wong and Ling's gross $\left(P_{\mathrm{R}}\right)$ and active $\left(P_{\mathrm{Zr}}\right)$ powers is significant. It is important to mention that the calculations in this work were made after applying a digital $100-\mathrm{Hz}$ low-pass first-order filter in the signals, similar to what was used in the primal paper (a $100-\mathrm{Hz}$ analog filter, without further specification). This cut-off frequency might be too low for welding signals,

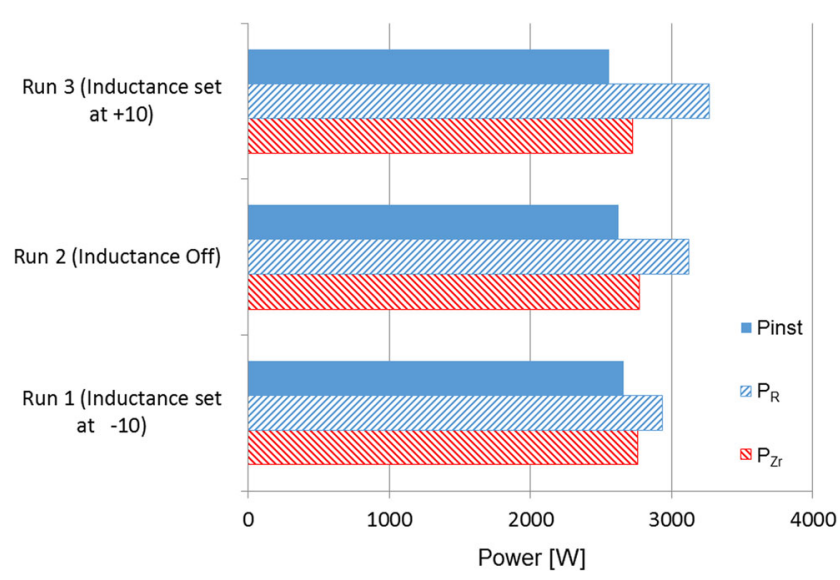

Fig. 6 Values of average instantaneous $\left(P_{\text {inst }}\right)$ and Wong and Ling's gross $\left(P_{\mathrm{R}}\right)$ and active $\left(P_{\mathrm{Zr}}\right)$ powers from the different parameterizations in Table 3

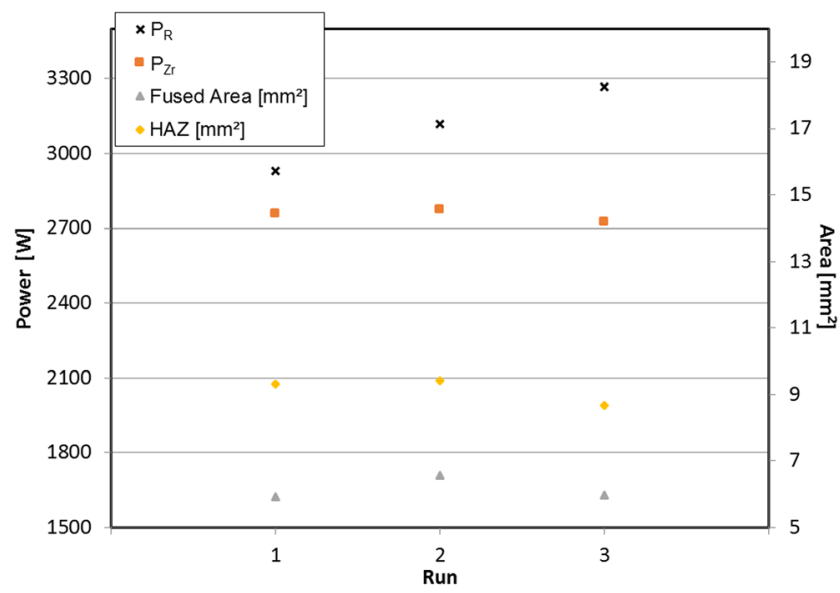

Fig. 7 Relationship between bead cross-section (fused area) and heataffected zone (HAZ) areas (average of three cross-sections) and Wong and Ling's gross $\left(P_{\mathrm{R}}\right)$ and active $\left(P_{\mathrm{Zr}}\right)$ powers

considering, for instance, that the increase and decrease of current and voltage during the short-circuit transfers (excluding the arcing time) take from 2 to $4 \mathrm{~ms}$. The filter can distort signals, affecting effective values of current and voltage, which increases the uncertainty of the power calculations.

Todoran et al.'s work [14] succeeds with the application of the Hilbert transform in ideal circuits with reactance. However, even in AC circuits, divergences on application of the Hilbert transform are found in current literature. Zhelbakov et al. [15], comparing methods of measuring reactive power, concluded that the method based on the discrete Fourier transform of the current and voltage is the most accurate. The authors of the current work recognize that it is necessary to decompose the signals in Fourier series and to remove the DC component to determine the phase shift between voltage and current and find the reactive energy. However, they consider it important to say that the theory of electric circuits is normally applied to systems with steady load, that is, the passive components (RLC) keep the same value (are not time-dependent). In welding, the arc (load) varies with time for several reasons, which can lead to the interpretation that there is some reactive element in the circuit. Other reasons for misinterpretations would be unbalanced analog filters for voltage and current signals, considering the inherent inaccuracy of electronic components, low response time of the current probe and cable inductance (Wong and Ling collected the signals at the power source terminals). Thus, using either the Hilbert or Fourier transform on arc signals, these arc variations can induce a fake presence of reactive component.

The model of the welding arc utilized by Wong and Ling [5] might also explain the lack of correlation between $P_{\mathrm{Zr}}$ and the heat onto/into the plate. These authors represented an arc as an RLC circuit, which presents a resonance characteristic. For some period, RLC could simulate an arc and it would 

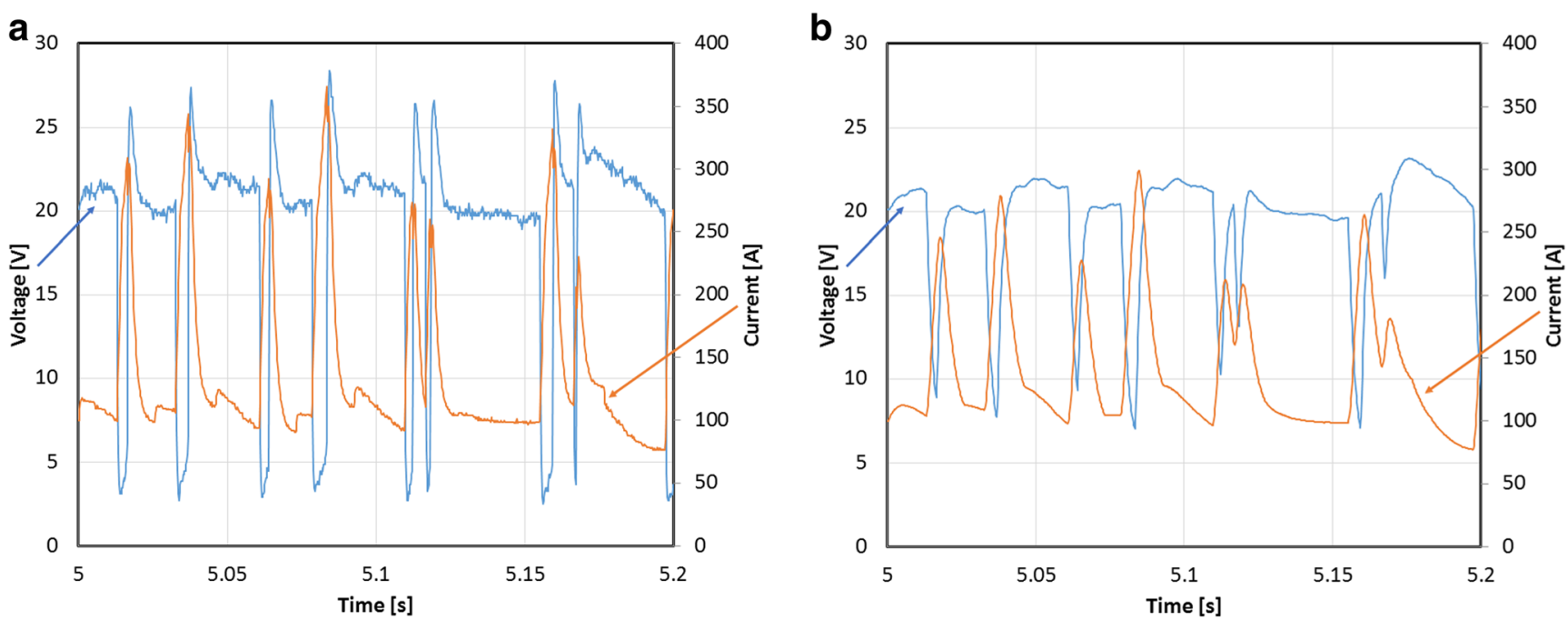

Fig. 8 Signals acquired from run 3 in Table 3. a Without a filter applied to the signals. b With a 100-Hz low-pass first-order digital filter applied

justify a reactance effect in the current and voltage signal. Nevertheless, it would not happen under DC voltage source powering the circuit. For instance, as an RLC circuit, the capacitor would be fully charged due to the open voltage of the power supply and current would become null. In addition, if a pulse of current is applied over an RL circuit, a voltage surge would appear in the di/dt transition, a fact that is not noticed in welding arc. Therefore, an RLC circuit does not represent a welding arc very well.

On the other hand, the authors of this work recognize that to model the arc as an equivalent electrical circuit does not seem to be an easy task. Rossi et al. [16], for instance, claim that the arc column should not be treated as a pure ohmic electrical resistance and the voltage drop in the plasma column would be a function mainly of the energy needed for a recurrent and constant reionization of the arc column atoms. However, they also warn that nothing is wrong with an electrical resistance analogy for the arc column, especially when applied in mathematical modelling of the arc and its effects.

Even though being difficult, effort has been placed on modelling the welding arc for different purposes. Examples of electrical circuit analogy application on arc modelling are given by Kodama et al. [6], for whom $\operatorname{arc}$ voltage $\left(U_{\mathrm{a}}\right)$ is expressed by $U_{\mathrm{a}}=U_{\mathrm{ao}}+R_{\mathrm{a}} \cdot I+E_{\mathrm{a}} L_{\mathrm{a}}$, where $U_{\mathrm{ao}}$ is a constant component of arc voltage, $R_{\mathrm{a}}$ the electric resistance of the arc column, $E_{\mathrm{a}}$ the electric field intensity in the arc column and $L_{\mathrm{a}}$ the arc length. Another representation is from Ngo et al. [7], who described that the average voltage output of a GMAW power source can be represented by $U_{\mathrm{a}}=\left(R_{\mathrm{s}}+R_{\mathrm{p}}+R_{\mathrm{n}}\right) I+$ ( $\left.U_{\mathrm{w}}+U_{\text {sheath }}\right)$ when the arc is ON, where $U_{\mathrm{a}}, R_{\mathrm{s}}, R_{\mathrm{p}}$ and $R_{\mathrm{n}}$ represent, respectively, the average output voltage of the power source, the resistance of the power source, the parasitic resistance in the circuit and the resistance between the contact tip and the wire. $U_{\mathrm{w}}$ and $U_{\text {sheath }}$ would represent the voltage drop between the electrode and the pool. Finally, the example of arc representation from Terasaki and Simpson's paper [8] is through the equation $U_{\mathrm{a}}(t)=118.6 \exp \left\{-0.0857\left[L_{\mathrm{a}}(t)+\right.\right.$ $1.054]-1\} \exp \{-0.000487[I(t)+349.2]-1]$. As seen, all representations are based on the existence of two parameters, resistance $(R)$ and potential energy drop $(E)$, i.e. an ER equivalent circuit. Reactance is not included.

The authors of the present paper are in closer agreement with the ER representation for an arc rather than with the RLC representation. However, the way they represent the arc model is as seen in Eq. 7, where $U_{\mathrm{a}}(t)$ is the instantaneous voltage collected between the contact tip and the plate and $I(t)$ would be the instantaneous current being carried along the circuit at the same time as voltage is measured. $R_{\mathrm{t}}$ is the summation of all true time-dependent resistive segments of the circuit, namely, the resistances between the contact tip and the wire, of the free electrode extensions, of the droplet under formation and of the weld pool (neglecting the resistance of other circuit parts, such as plate and cables). $E$, in turn, would represent the potential energy to overcome the needs to maintain the arc column and the couplings arc-electrode/droplet and arc-weld pool. That is, $E$ corresponds to the energy supplier, like any power source. $E$ depends on the plasma atmosphere, but is also time-dependent, since arc size varies with current level and arc length.

$U_{\mathrm{a}}(t)=E(t)+R_{\mathrm{t}}(t) \cdot I(t)$

The model of Eq. 7 was deduced from observations of the arc electrical dynamics. If current and voltage signals during a process operation are recorded at a high sample rate during a period and the ordered pairs are plotted in an $I-U$ coordinate plane, an arc work regime plot is established. These plots are likely the best means of depicting the arc behaviour, because the dynamic behaviour of the arc is expressed on a finite plane. 

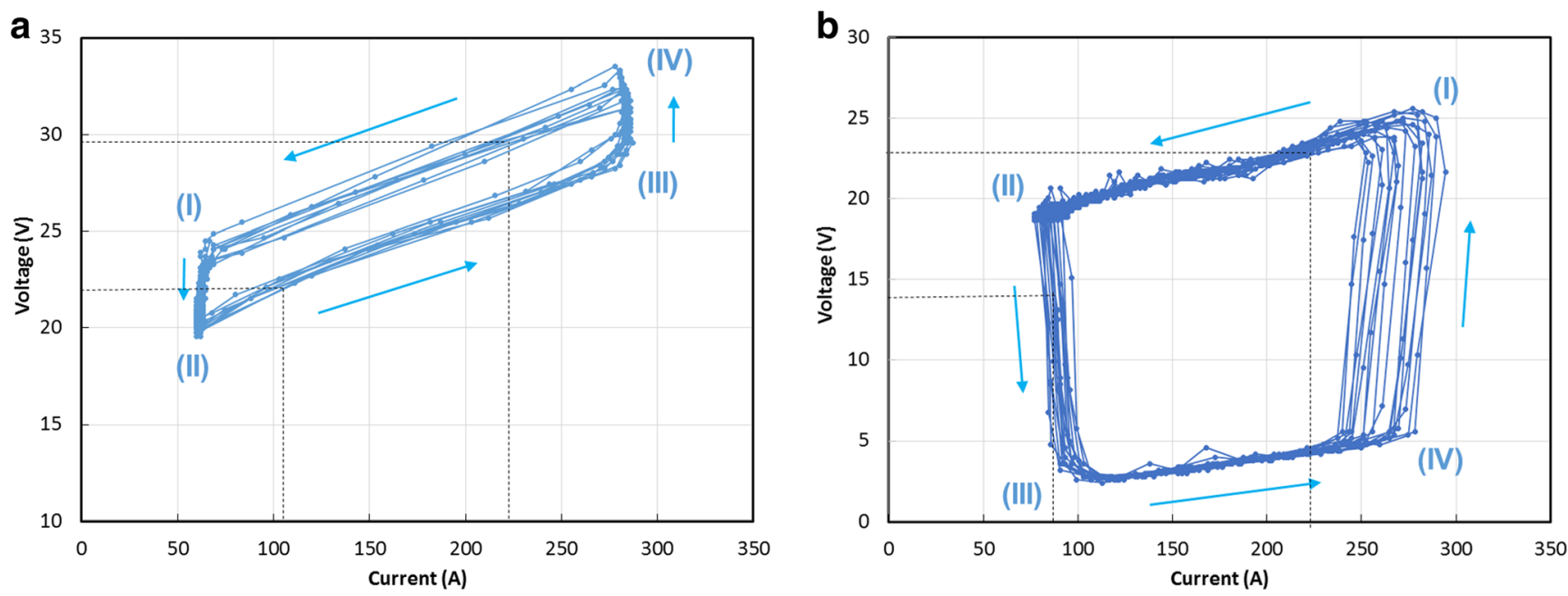

Fig. 9 Work regime of welding processes after several cycles at a given parameter setting. a Pulsed GMAW. b Short-circuit GMAW process

For instance, in Fig. 9a, an arc related to pulsed GMAW is presented. From I to II, the arc is in the base period, with low current and voltage, and from III to IV, in the pulse period, with high current and voltage. The base to pulse and pulse to base transients are from II to III and from IV to I, respectively. At each ordered pair, there will be a corresponding voltage. A portion of this voltage is related to the resistive components, and the remaining is due to the described potential energy $(E)$. As the demanded $E$ and the product $R_{\mathrm{t}} . I$ are lower for lower currents, $U_{\mathrm{a}}$ will be smaller.

Consider now Fig. 9b, from a conventional short-circuit GMA welding. The arcing time starts when current is at the highest (short-circuit current), indicated by (I). The current and voltage decrease steadily during this period until the arc is short-circuited (II). A droplet is formed at the wire tip. Then, voltage drops sharply to a low value and current increases slightly (III), in a transient status. From (III) to (IV), the droplet at the wire end is short-circuiting the pool, forming a viscous metallic bridge between the droplet and pool surface (short-circuit time). As the temperature of the system is progressively decreasing and the bridging is narrowing its diameter (surface tension sucking the droplet, necking the metallic bridge), the electrical resistance and consequently voltage increase at the same pace (so does the current, due to the power source characteristic). The arc starts again from IV to I, with a steep voltage increase (another transient period). In shortcircuiting transfer, there are two reasonably steady regimes: arcing time, which could be represented by an ER circuit, and the short-circuit time, represented only by an R circuit. One can figure out an arc work regime plot for a GTAW welding with constant current; there would be just a point of coincident ordered pairs or, at most, a cluster of ordered pairs close together.

That being said and demonstrated, active power in arc welding would be the total arc power. Consequently, all electric energy consumed in the process is basically transformed into heat, which goes in its majority onto/ into the plate and a fraction is lost to the environment. The reason for Wong and Ling [5] having found active powers $\left(P_{\mathrm{Zr}}\right)$ differing from their arc power $\left(P_{\mathrm{R}}\right)$ calculations in some experiments would be that the use of the Hilbert transform in this case was inappropriate. It would be just one more method of calculation, without a physical support. Table 4 exemplifies this statement by showing all the calculated powers using the equations presented in this work. One can see that, except for the constant current parameterizations, each equation gives different results. However, as seen in Section 1, the average instantaneous power, quantified by Eq. 3, is the most justifiable method.

Table 4 Power (W) calculated by different equations using the same data

\begin{tabular}{|c|c|c|c|c|c|}
\hline Identification & $\begin{array}{l}P_{\text {arithmetical }} \\
\text { (Eq. 1) }\end{array}$ & $\begin{array}{l}P_{\text {effective }} \\
\text { (Eq. 2) }\end{array}$ & $\begin{array}{l}P_{\text {inst }} \\
\text { (Eq. 3) }\end{array}$ & $\begin{array}{l}P_{\mathrm{R}} \\
\text { (Eq. 4) }\end{array}$ & $\begin{array}{l}P_{\mathrm{Zr}} \\
\text { (Eq. 6) }\end{array}$ \\
\hline Run 1 - constant & 4924.9 & 4924.9 & 4923.7 & 4920.2 & 4920.2 \\
\hline $\begin{array}{l}\text { Run 2-pulsed } \\
300 / 4005 \mathrm{~Hz}\end{array}$ & 5124.3 & 5189.7 & 5174.7 & 5179.3 & 5120.5 \\
\hline $\begin{array}{l}\text { Run 3-pulsed } \\
200 / 5005 \mathrm{~Hz}\end{array}$ & 5583.1 & 6035.3 & 5910.5 & 6063.8 & 5429.9 \\
\hline $\begin{array}{l}\text { Run } 4 \text {-pulsed } \\
\text { 200/500 } 10 \mathrm{~Hz}\end{array}$ & 5658.8 & 6109.4 & 5986.7 & 6123.2 & 5497.1 \\
\hline $\begin{array}{l}\text { Run } 1 \text { - pulsed } \Delta I \\
\quad 0 ; I_{\mathrm{m}} 249\end{array}$ & 3234.5 & 3234.5 & 3234.5 & 3234.5 & 3233.1 \\
\hline $\begin{array}{l}\text { Run } 2-\text { pulsed } \Delta I \\
0 ; I_{\mathrm{m}} 224\end{array}$ & 2841.0 & 2841.0 & 2841.0 & 2841.0 & 2837.5 \\
\hline $\begin{array}{l}\text { Run 3-pulsed } \Delta I \\
0 ; I_{\mathrm{m}} 206\end{array}$ & 2667.2 & 2667.2 & 2667.2 & 2667.2 & 2666.8 \\
\hline $\begin{array}{l}\text { Run } 4 \text { pulsed } \Delta I \\
100 ; I_{\mathrm{m}} 200\end{array}$ & 2466.9 & 2600.6 & 2560.1 & 2638.1 & 2528.0 \\
\hline $\begin{array}{l}\text { Run 5-pulsed } \Delta I \\
\text { 200; } I_{\mathrm{m}} 200\end{array}$ & 2557.2 & 2934.3 & 2796.5 & 3188.0 & 2603.3 \\
\hline $\begin{array}{l}\text { Run } 6 \text { - pulsed } \Delta I \\
\quad 300 ; I_{\mathrm{m}} 200\end{array}$ & 2557.9 & 3181.2 & 2876.0 & 4816.0 & 2486.9 \\
\hline $\begin{array}{l}\text { R1 (-10 } \\
\text { inductance) }\end{array}$ & 2497.9 & 3007.0 & 2658.2 & 2931.8 & 2756.0 \\
\hline $\begin{array}{l}\text { R2 (inductance } \\
\text { OFF) }\end{array}$ & 2345.9 & 3005.7 & 2621.0 & 3119.0 & 2771.5 \\
\hline $\begin{array}{l}\text { R3 (+10 } \\
\text { inductance) }\end{array}$ & 2142.8 & 3143.0 & 2555.1 & 3267.3 & 2725.3 \\
\hline
\end{tabular}




\section{Conclusion}

In this paper, the question whether inductive and/or capacitive reactance is present or not in a welding arc, reflecting on arc power and heat input measurements, was addressed. The present experimental methodology and results and data analyses led to the conclusion that the arc (not the welding circuit) is a reactance-free (inductive or capacitive) load and, consequently, there is no power component such as non-active power. Equation 3, for instance, can be used in any circuit or conditions, such as AC, DC, and steady and variable loads. Therefore, all net power (excluding losses to the environment) is consumed in heat generation and transferred to the plate, as have been traditionally assumed. In addition, the authors also conclude that a model of arc would be composed of a potential energy and an electrical resistance, yet both components are time-dependent if the arc changes sizes in a transitorily manner.

Acknowledgments The authors would like to thank the Center for Research and Development of Welding Processes (Laprosolda) of the Federal University of Uberlandia and the welding machine manufacturer IMC, Brazil, for the welding infrastructure and technical support. They also thank the Brazilian agencies for research development CNPq (process 302091/2011-4) and CAPES (Proc. Auxpe 0309/2015) for awarding research and studying grants. Last, but not least, they are very grateful to their colleagues MSc Diego Silva and MSc Daniel Souza, for having provided their practical results, which were also used in the analysis of this work.

Open Access This article is distributed under the terms of the Creative Commons Attribution 4.0 International License (http:// creativecommons.org/licenses/by/4.0/), which permits unrestricted use, distribution, and reproduction in any medium, provided you give appropriate credit to the original author(s) and the source, provide a link to the Creative Commons license, and indicate if changes were made.

\section{References}

1. Bosworth MR (1991) Effective heat input in pulsed gas metal arc welding with solid wire electrodes. Weld J 70(5):111s-117s

2. Joseph A, Harwig D, Farson DF, Richardson R (2003) Measurement and calculation of arc power and heat transfer efficiency in pulsed gas metal arc welding. Sci Technol Weld Join 8(6):400-406

3. Nascimento AS, Batista MA, Nascimento VC, Scotti A (2007) Assessment of electrical power calculation methods in arc welding and the consequences on the joint geometric, thermal and metallurgical predictions. Soldagem e Inspeção 12(2):97-106 (in Portuguese)

4. Melfi T (2010) New code requirements for calculating heat input. Weld J 9(6):61-65

5. Wong YR, Ling S-F (2013) Improved measurement of resistance and calculation of arc power in fusion welding. Sci Technol Weld Join 18(1):52-56. doi:10.1179/1362171812Y.0000000074

6. Kodama S, Ichiyama Y, Ikuno Y, Baba N (2007) Process modeling of short-circuiting GMA welding and its application to arc sensor control. Nippon Steel Technical Report 95(1):71-75

7. Ngo MD, Duy VH, Phuong NT, Kim HK, Kim SB (2007) Development of digital gas metal arc welding system. J Mater Process Technol 189(1):384-391. doi:10.1016/j.jmatprotec.2007. 02.010

8. Terasaki H, Simpson SW (2005) Modelling of the GMAW system in free flight and short-circuiting transfer. Sci Technol Weld Join 10(1):120-124. doi:10.1179/174329305X29528

9. Wong YR, Ling S-F (2013) Novel classification method of metal transfer modes in gas metal arc welding by real time input electrical impedance. Sci Technol Weld Join 19(3):24-230. doi:10.1179/ 1362171813Y.0000000184

10. Silva DCC, Scotti A (2017) Using either mean or RMS values to represent current in modeling of arc welding bead geometries. J Mater Process Technol 240:382-387. doi:10.1016/j.jmatprotec. 2016.10.008

11. Hurtig K, Choquet I, Scotti A, Svensson L-E (2016) A critical analysis of weld heat input measurement through a water-cooled stationary anode calorimeter. Sci Technol Weld Join 21(5):339 350. doi:10.1080/13621718.2015.1112945

12. Liskevych O, Quintino L, Vilarinho LO, Scotti A (2013) Intrinsic errors on cryogenic calorimetry applied to arc welding. Weld World 57(3):349-357. doi:10.1007/s40194-013-0035-5

13. Liskevych O, Scotti A (2015) Determination of the gross heat input in arc welding. J Mater Process Technol 225:139-150. doi:10.1016/ j.jmatprotec.2015.06.005

14. Todoran G, Muntean O, Buzura A (2013) Determination of active and reactive power in multi-phase systems through analytical signals associated current and voltage signals. Acta Electrotehnica 54(2):156-159

15. Zhelbakov, I.N., Serov, A.N., Shatokhin, A.A. (2011). A comparative analysis of methods of measuring reactive power, Meas Tech 54(1). doi:10.1007/s11018-011-9684-1

16. Rossi ML, Ponomarev V, Scotti A (2016) Heat exchange and voltage drop in welding arc column. IEEE Trans Plasma Sci 44(99):19. doi:10.1109/TPS.2016.2606628 